\title{
Metal Colloids and Quantum Dots: Linear and Nonlinear Optical Properties
}

Fisk University

Physics Department

Nashville, TN 37208

May 12, 1997

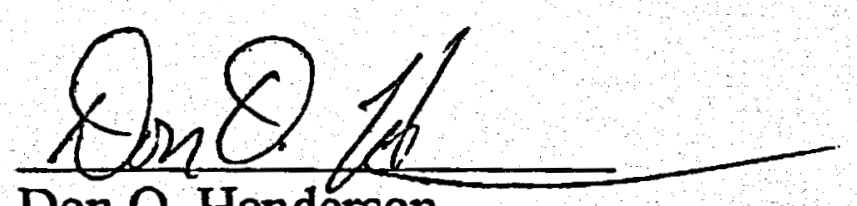

Don 0 . Henderson

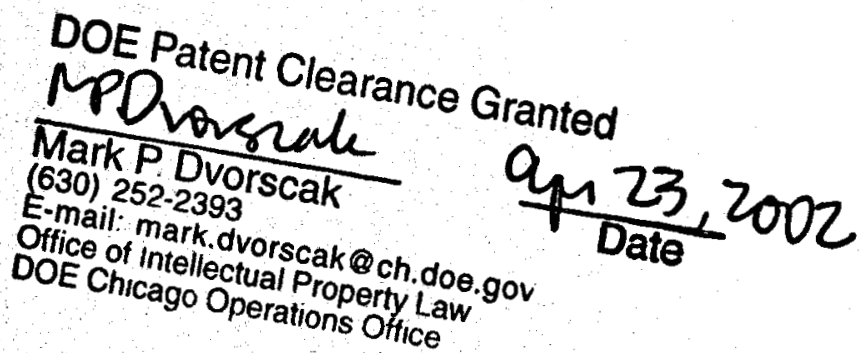




\section{DISClaIMER}

This report was prepared as an account of work sponsored by an agency of the United States Government. Neither the United States Government nor any agency thereof, nor any of their employees, makes any warranty, express or implied, or assumes any legal liability or responsibility for the accuracy, completeness, or usefulness of any information, apparatus, product, or process disclosed, or represents that its use would not infringe privately owned rights. Reference herein to any specific commercial product, process, or service by trade name, trademark, manufacturet, or otherwise does not necessarily constitute or imply its endorsement, recommendation, or favoring by the United States Government or any agency thereof. The views and opinions of authors expressed herein do not necessarily state or reflect those of the United States Governmeat or any agency thereof. 


\section{DISCLAIMER}

Portions of this document may be illegible in electronic image products. Images are produced from the best available original document. 


\section{Background}

Nanophase materials have found a wide application in a variety of technological areas which include ultrafast optical switching, high density information storage and retrieval, electronics, and catalysts, to mention a few. Nanocrystal science has also drawn considerable interest from the fundamental perspective engaging physicists, chemists, and material scientists into this area of rapidly expanding and challenging research Basic questions concerning how matter evolves from atomic like behavior to molecular and onto bulk lie at the center nanocrystal research. In addition, because of the high surface to volume ratio of the nanocrystals, the interaction potential between a nanocrystal and its surrounding environment becomes an important issue in determining its properties. While significant progress has been made in nanocrystal research, there are many problems concerned with their fabrication. In particular, the difficulty of incorporating nanocrystals into a matrix that is appropriate for ultimate device development has hindered some aspects of nanocrystal research. Ion implantation is a method that is now established as a technique for fabricating metal and semiconductor nanocrystals. It is highly versatile in that one may select nearly any host material for incorporating the nanocrystals of interest. The flexibility of being able to select the host matrix is also interesting from the point of view that it opens the opportunity to investigate matrix-nanocrystal interactions. We summarize in the following sections results on metal and semiconductor nanocrystals formed by ion implantation into dielectric hosts.

\section{Metal Nanocrystals, Progress ${ }^{1}$}

Metal nanocrystals are particularly interesting in that they possess a large polarizability. The large polarizability which originates from the surface plasmon resonance is expected to enhance the third order nonlinear susceptibility $\chi^{(3)}$. Enhancement of $\chi^{(3)}$ is important because the real part is responsible for many processes based on optical bistability such as optical switching. Consequently, it is essential that the linear optical response of metal nanocrystals be fully characterized in order to understand the optical nonlinearities.

\subsection{Gold Nanocrystals}

Gold nanocrystals were formed in $\mathrm{MgO}$ and porous Vycor Matrices. The gold nanocrystals in MgO are discussed first.

Single crystal substrates of $\mathrm{MgO}$ cut $(100)$ were used for implantation. Ions doses between $1 \times 10^{16}$ and $1 \times 10^{17}$ ions $/ \mathrm{cm}^{2}$ were implanted at room temperature at an energy of $1.1 \mathrm{MeV}$. The substrates were annealed at temperatures between 900 and $1200^{\circ} \mathrm{C}$ in $95 \% \mathrm{Ar}+5 \% \mathrm{H}_{2}$ and $95 \% \mathrm{Ar}+5 \% \mathrm{O}_{2}$ atmospheres. Optical spectra were measured before and after the annealing treatments. The asimplanted samples showed peaks at 575 and $530 \mathrm{~nm}$ which are assigned to $F_{\mathrm{q}}$ centers and the surface plasmon absorption of gold nanocrystals, respectively. Annealing the samples in the oxidizing atmosphere caused the peak at $530 \mathrm{~nm}$ to shift to $560 \mathrm{~nm}$. Annealing the same sample in a reducing atmosphere caused the peak at $560 \mathrm{~nm}$ to shif back to $530 \mathrm{~nm}$. This process cycles as many as 30 times. We have interpreted that this frequency shift arises from the gold nanocrystals interacting with the $F_{n}$ centers. When the sample is annealed in a reducing atmosphere, $F_{n}$ centers are generated. These

'Details of results can be found in Appendix A.Reprints 
centers then inject electrons (the Fermi level is lower for gold than the F centers) into the gold nanocrystal causing the surface plasmon frequency to blueshif. Annealing the substrates in an oxidizing atmosphere annihilates the $F_{\mathrm{n}}$ centers causing the surface plasmon frequency to return 530 $\mathrm{nm}$. The particular significance of these results lies in the fact that information concerning the interface between the gold nanocrystal and the $\mathrm{MgO}$ matrix has been obtained. This clearly demonstrates that effective medium theories (Maxwell Garnett, Bruggeman, etc) cannot account for interface effects such as the ones just noted and care should be taken when evaluating the quality of experimental data with effective medium theories.

Gold was implanted into porous Vycor substrates at $1.1 \mathrm{MeV}$ and at doses from $1 \times 10^{16}$ to $1 \times 10^{17}$ ions $/ \mathrm{cm}^{2}$. The samples were annealed in a $95 \% \mathrm{Ar}+5 \% \mathrm{H}_{2}$ atmosphere at temperatures from 800 to $1100^{\circ} \mathrm{C}$. The vibrational and electronic spectra were recorded before and after the annealing treatments. The surface plasmon absorption was observed at $540 \mathrm{~nm}$ and increased in intensity with increasing annealing time and temperature. An additional mode also appeared near $900 \mathrm{~nm}$ after annealing and was assigned to a second surface plasmon absorption that resulted from the removal of the spherical symmetry of the nanocrystals. This occurs by anisotropic shrinkage of the glass which is larger in the radial direction than in the axial. The spectra were reproduced using Maxwell Garnett theory for prolate ellipsoids. The fit was within a few percent error and confirmed the particles were prolate ellipsoids.

\subsection{Zinc Nanocrystals}

Zinc ion implanted silica with controlled thermal annealing was investigated. Low temperature measurements indicate the presence of Zn clusters in the as-implanted samples. Optical spectra of the samples annealed under a reducing environment suggest $\mathrm{Zn}$ cluster and $\mathrm{Zn}$ colloid formation. An absorption peak at $5.3 \mathrm{eV}$ may be due to the surface plasmon absorption of $\mathrm{Zn}$ colloids. The samples annealed in a oxidizing atmosphere show peaks near 4.3 and $4.8 \mathrm{eV}$ indicating $\mathrm{ZnO}$ quantum dot formation. The blueshift of the exciton is attributed to quantum confinement effects.

\section{Semiconductor Nanocrystals, Progress ${ }^{l}$}

Semiconductor nanocrystals intrigue scientists for a number of reasons. They offer the opportunity for testing theories based on quantum size effects, and they are rich candidates for optical devices. Such devices inchude: flat panel displays, nanostructure lasers, and narrow spectrum resonant cavity emitting diodes are just some examples.

\subsection{Silicon}

Silicon nanocrystals were formed by high dose $\mathrm{Si}$ implantation into a $\mathrm{SiO}_{2}$ film on silicon. Multiple energy implants were used to produce an excess Si concentration of $5 \times 10^{21} / \mathrm{cm}^{3}$ throughout the film and the implanted sample was annealed subsequently at $1100^{\circ} \mathrm{C}$ for 1 hour in a $96 \% \mathrm{Ar}+4 \% \mathrm{H}_{2}$ atmosphere. Under these conditions, the average nanocrystal size was $-4 \mathrm{~nm}$ in diameter and very few exceeded $8 \mathrm{~nm}$. The nanocrystals exhibited strong photoluminescence $(\mathrm{PL})$ in the wavelength range of $750 \mathrm{~nm}$ although the origin is not known. By comparison to the photoluminescence of porous silicon, the intensity and stability of the PL from the nanocrystals was greater than that of porous silicon. The formation of the nanocrystals was also confirmed by cross sectional TEM measurements.

\subsection{Silicon-Germanium Alloy}

$\mathrm{SiGe}$ nanocrystal alloys were formed by sequential ion implantation of $\mathrm{Si}$ and $\mathrm{Ge}$ into a layer of $\mathrm{SiO}_{2}$ 
on a silicon substrate. The sequence of the implants were found to significantly effect the nanocrystal formation and was attributed to ion beam mixing. The formation of the nanocrystals was confirmed by cross sectional TEM and by $x$-ray diffraction measurements. When the samples were implanted with $\mathrm{Ge}$ and then $\mathrm{Si}$ followed by annealing at $1100^{\circ} \mathrm{C}$ the nanocrystals are much larger than when the sequence is $\mathrm{Si}$ followed by $\mathrm{Ge}$. It is expected that this finding is general for compound semiconductors formed by sequential ion implantation and will be exploited in the future for affecting size control of the quantum dots.

\subsection{Gallium Arsenide}

Quantum dots of $\mathrm{GaAs}$ were formed by sequential ion implantation into $\mathrm{Al}_{2} \mathrm{O}_{3}$ and $\mathrm{SiO}_{2}$. The crystals are randomly oriented in silica and less than $15 \mathrm{~nm}$ in diameter. In the $\mathrm{Al}_{2} \mathrm{O}_{3}$ matrix, the nanocrystals are three dimensionally aligned with respect to the crystal lattice. Infrared reflectance measurements show the surface phonon mode of GaAs nanocrystals and it agrees well with the value predicted by Frölich's theory of surface phonons. Also, strong inhomogeneous broadening is observed for the GaAs nanocrystals isolated in $\mathrm{SiO}_{2}$ as compared to the $\mathrm{Al}_{2} \mathrm{O}_{3}$ matrix. The presence of the nanocrystals was confirmed by TEM, XRD and infrared spectroscopy.

\subsection{Gallium Phosphide and Indium Phosphide}

Both InP and GaP were synthesized in silica by sequential ion implantation. Quantum confinement effects were observed in the electronic spectra. Infrared spectroscopy revealed the surface phonons of both materials and were found to be in good agreement with Frölich's theory. TEM images of InP showed extensive twinning among the nanocrystals. $X$-ray diffraction measurements confirmed that InP had been formed.

\subsection{Lead Sulfide}

Nanocrystals of this narrow gap semiconductor were fabricated in (111) cut $\mathrm{CaF}_{2}$ single crystals. The appearance of a peak near $600 \mathrm{~nm}$ for the sequentially implanted substrate suggested quantum confinement. The peak blueshifted as the ion dose decreased which is consistent quantum confinement theory.

\subsection{Selenium}

Selenium was implanted into fused silica at dose of $1 \times 10^{17}$ ions $/ \mathrm{cm}^{2}$ and annealed at 600,800 , and $1000^{\circ} \mathrm{C}$. The optical spectra showed an absorption onset near $2.5 \mathrm{eV}$ that redshifted as the annealing temperature increased. This absorption onset is consistent with the bulk value (no quantum confinement effects) expected for trigonal selenium. However, selenium also exists in a monoclinic form which has a band gap of $1.95 \mathrm{eV}$ suggesting that the absorption onset of $2.5 \mathrm{eV}$ could be attributed to quantum confined monoclinic selenium.

\section{Students}

Chrisptopher Hall completed his M.S. in the spring semester of 1996. His masters thesis was on Indium Phosphide quantum dots formed by ion implantation fused silica. He has been accepted at Meharry Medical School where he is currently a student. A new graduate student, Taravia Taylor just joined the group and will work on nanocrystal reserach. Ms. Taylor should graduate in Fall 1999.

Last summer, four students Osaze Scott, Mike Mackay, Omari Jones, and Angela Allen participated in a summer intern program sponsored by NSF. All four students worked on nanocrystals and Osaze 
Scott and Mike Mackay shared authorship on a paper entitled "Gold Implanted Calcium Fluoride Single Crystals: Optical Properties of Ion Induced Defects and Metal Nanocrystals" published in Materials Forum 239-241, 695 (1997). Two new summer interns are expected for this year and will work on nanocrystals.

\section{Publications}

Gold Implanted in Porous Vycor Glass: Size and Shape Effects on the Surface Plasmon of Gold Nanocrystals" D. O. Henderson, A. Ueda, R. Mu, Y. S. Tung, M. Wu, Jinli Chen, Z. Gu, C. W. White, R. Zuhr, Jane, G. Zhu, and $X_{I} \mathrm{Li}$, Accepted for publication in the Proceedings of the Electrochemical Society (1977).

"Ion Beam Synthesis of Nanocrystals and Quantum Dots in Optical Materials," C. W. White, J. D. Budai, S. P. Withrow, J. G. Zhu, S. J. Pennycosck, R. H. Magruder, and D. O. Henderson

"Encapsulated Nanocrystals and Quantum Dots Formed by Ion Beam Synthesis," C. W. White, J. D. Budai, S. P. Withrow, J. G. Zhu, S. J. Pennycook, R A Zuhr, D. M Hembree, D. O. Henderson, D. O. Henderson, R. H Magruder, M. J. Yacaman, G. Mondragon, and S. Prawer, accepted for publication Nuclear Instruments and Methods (1996).

"Optical and Structural Characterization of Zinc Implanted Silica Under Various Thermal Treatments" R Mu, Z. Y. Gu, Y. -S. Tung, D. O. Henderson, C. W. White, Jane G. Zhu, John D. Budai, and R. A. Zuhr, accepted for publication in MRS proceedings (1996)

"Carbon Implanted in Optical Grade Fused Silica: Annealing Effects in Reducing and Oxidizing Atomospheres" Y. -S. Tung, R. Mu, A. Ueda, D. O. Henderson, P. W. Wang, C. W. White, Jane G. Zhu, and R. A. Zubr, accepted for publication in MRS proceedings (1996).

"Gold Implanted in Calcium Fluoride Single Crystals: Optical Properties of Ion Induced Defects and Metal Nanocrystals", D. O. Henderson, Y.-S. Tung, A Ueda, Jinli Chen, Z. Gu, C. W. White, Jane G. Zhu, C. W. White, M. McKay, and O. Scoth, Materials Forum, 239-241 695 (1997).

"Annealing Effects on the Surface Plasmon of MgO implanted with Gold", A Ueda, R. Mu, Y.-S Tung, C. W. White, R A Zuhr, Jane G. Zhu, and P. W. Wang, Materials Form, 239-241 675 (1997).

"Au Ion Irradiated Muscovite Mica: Infrared and Optical Properties off Defects and Metal Nanocrystals" Y.-S. Tung, D. O. Henderson, JinLi Chen, Z. Gu, A Ueda, R. Mu, C. W. White, Jane G. Zhu, and R Zuhr, Materials Forum, 239-241691 (1997).

"Chemical and Size Characterization of of Layered Lead Iodide, Quantum Dots via Optical Spectroscopy and Atomic Force Microscopy", J. Phys. Chem, 10019927 (1996).

"GaAs Nanocrystals formed by Sequential Ion Implantation", C. W. White, J. D. Budai, J. G. Zhu, S. P. Withrow, D. M Hembree, D. O. Henderson, A Ueda, Y-S. Tung, and R. H. Magruder, J. Appl. Phys., 79, 1876 (1996). 
"Electronic and Vibrational Spectra of InP Quantum Dots Formed by Sequential Ion Implantation", R. Mu, D. O. Henderson, Y-S. Tung, A.Ueda, C. Hall, W. E. Collins, C. W. White, R. A. Zuhr, and Jane G. Zhu, J. Vac. Sci. Technol., A14, 1482 (1996).

"Atomic Force Microscopy of Merctry Iodide Crystal Growth From Porous Media at Room Temperature" D. O. Henderson, Y-S. Tung, A. Ueda, W. E. Collins, A. Burger, K. T. Chen, D. O. Frazier, J. Vac. Sci. Technol. A14, 1083.(1996).

"Optical Response From the Ultraviolet to the Far-Infrared and Atomic Force Microscopy of Au Implanted in In $\mathrm{CaF}_{2}$ ", D. O. Henderson, Y-S. Tung, A. Ueda, R. Mu, C. Hall, W. E. Collins, C. W. White, R A. Zuhr, Jane G. Zhu, and Paul. W. Wang, J. Vac. Sci. Technol. A14, 1199 (1996).

"Formation of Crystalline Germanium Nanoclusters in a Silica Xerogel Matrix from an Organogermanium Precursor", Joseph P. Carpenter, C. M Lukehart, D. O. Henderson, R. Mu, Bobby D. Jones, R. Glosser, S. R. Stock, James Wittig, Jane G. Zhu, Chem. Mat. 8, 1268 (1996).

"Effects on Ion Beam Mixing on the Formation of SiGe Nanocrystals by Ion Implantation" Jane G. Zhu, C. W. White, J. D. Budai, S. P. Withrow, and D. O. Henderson, accepted for publication in IEEE (1997).

"Surface Phonon Characterization of InP, GaP, and GaAs Quantum DotsConfined in Dielectric Hosts", D. O. Henderson, A. Uede, Y-S. Tung, R. Mu, C. W. White, R. A. Zuhr, and J. G. Zhu, J. of Physics D: Applied Physics 301432 (1997).

"Stark Effects, Band Gaps and Surface Phonons in of Semiconductor Quantum Dots in Dielectric Hosts" R Mu, A Ueda, Y.-S. Tung, D. O. Henderson, Jane G. Zhu, J. Budai, C. W. White, and R. A. Zuhr, Mat. Res. Symp. Proc., (in press, 1996).

"Nanocrtystals and Quanturm Dots formed by High Dose Ion Implantation" C. W. White, J. D. Budai, Jane. G. Zhu, S. P. Withrow, D. M Hembree, D. O. Henderson, A. Ueda, Y.-S. Tung, R. Mu, Mat. Res. Symp. Proc., 405127 (1996)

"Vibrational and Electronic Transitions in InAs Quantum Dots formed by Sequential Ion Implantation", A Ueda, R Mu, Y.-S. Tung, C. Hall, Jane G. Zhu, C. W. White, and R Zuhr, Mat. Res. Symp. Proc., 396441 (1996).

"Scanning Tunneling Microscopy and Atomic Force Microscopy of Au Implanted in Highly Ordered Pyrolytic Graphite", Y.S. Tung A Ueda, D. O Henderson, R Mu, C. W. White, R. A. Zuhr, and Jane G. Zhu, Mat. Res. Symp. Proc., 396223 (1996).

"Atomic Force Microscopy, electronic and Vibrational Spectroscopy of Au Colloids formed by Ion Implantation in Muscovite Mica, D. O. Henderson, R Mu, Y.S. Tung, C. W. White, and R A Zuhr, J. Non-Cryst. Solids, 205-207 788 (1996).

"Linear and Nonlinear Optical Response of Bismuth and Antimony Implanted in Silica: Annealing 
Effects", Z. Pan, S. H. Morgan, D. O. Henderson, S. Y. Park, R. A. Weeks, R. H. Magruder, and R. A. Zuhr, Optical Materials 4, 675 (1995).

"Atomic Force Microscopy of Au Implanted in Sapphire", D. O. Henderson, M. A George, A. Burger, R. Mu, S. H. Morgan, R. H. Magruder, C. W. White, and R. A Zuhr, J. Vac. Sci. Technol. B13, 1198 (1995).

"XPS and Infrared Spectroscopy of Cu Implanted Silica and Borosilicate Glasses, D. O. Henderson, M. A. George, Y.-S. Tung, A. Burger, S. H. Morgan, W. E. Collins, C. W. White, R. A. Zuhr and R. H. Magruder, J. Vac. Sci. Technol. A13, 1254 (1995).

"Compound Semiconductor Nanocrystals Formed By Sequential Ion Implantation", C. W. White, J. D. Budai, Jane G. Zhu, S. P. Withrow, R A. Zuhr, D. M. Hembree, R. H. Magruder, and D. O. Henderson, Mat. Res. Soc. Symp. Proc. 358, 169 (1995).

"Exciton and Phonon Confinement in Gap Quantum Dots" D. O. Henderson, R. Mu, Y.-S. Tung, A. Ueda, Proc. Electrochem. Soc. 95, 28 (1995).

"Nanocomposites from Molecularly Doped Silica Xerogels: An Overview" J. P. Carpenter, C. M. Lukehart, B. Milne, S. R. Stock, J. E. Wittig, B. D. Jones, R Gosser, D. O. Henderson, R. Mu, R. D. Shull, Jane G. Zhu, Z. U. Rek, SAMPE Tech. Conf, 27549 (1995). 